\title{
A Study on the Europeanization of the Chinese Language in Sci-Tech Translation Based on Skopos Theory
}

\author{
Chen Xiangyue \\ School of Translation Studies, Jinan University \\ Zhuhai, 519070, China \\ E-mail: 1916897995@qq.com \\ Lu Junyu \\ School of Translation Studies, Jinan University \\ Zhuhai, 519070, China \\ E-mail: lujunyu8312@163.com
}

He Rui

School of Translation Studies, Jinan University

Zhuhai, 519070, China

E-mail: h.h-horace@outlook.com

Zhang Ru (Corresponding author)

Finance Department of International Business School, Jinan University

Zhuhai, 519070, China

E-mail: zhangru@stu2016.jnu.edu.cn

Received: September 29, 2018 Accepted: October 11, 2018 Published: October 14, 2018

doi:10.5296/jsel.v6i1.13779 URL: https://doi.org/10.5296/jsel.v6i1.13779 


\begin{abstract}
As a bridge of scientific and technological communication between China and other countries, sci-tech translation is of great significance in promoting the social development of China in the current situation. Europeanization, particularly in sci-tech translation, refers to the general name of new expressions and sentence patterns emerged under the influence of European languages, especially English. From the perspective of Skopos theory and its core element (paying attention to the target addressees), this paper attempts to analyze Europeanization in sci-tech translation and to predict its future development and application, so that translators could get a better understanding of its present situation and prospect, and thus produce more idiomatic and faithful translations that achieve communicative goals better. This will finally contribute to the development of both theoretical research and practice of sci-tech translation.
\end{abstract}

Keywords: Skopos Theory, Sci-Tech Translation, Europeanization 


\section{Introduction}

In current situation, China's research in science and technology is increasingly connected with the international community, and a large number of scientific and technological documents are being translated every year. The importance of sci-tech translation study has become increasingly prominent. EST (English for science and technology) is mainly characterized by accuracy, objectivity and preciseness. In order to keep the same features in target version, both words and sentences in sci-tech translation are under particular consideration. As Mr. Wang Li put it, translation is easiest to be Europeanized. Due to this and the constant expanding influence of Europeanization, Europeanized Chinese inevitably appear in sci-tech translation. It is a brand-new topic to study the Europeanization from the perspective of sci-tech translation and based on Skopos theory.

\section{Introduction to Skopos Theory and Its Guidance for Sci-tech Translation}

\subsection{Introduction to Skopos Theory}

The core of Skopos theory lies on the concept that the dominant factor in translation is the aim or purpose of translation as an activity. In other words, the quality of TT (target text) should not only be judged by its faithfulness to the ST (source text), but also by the requirement for translation, the purpose of translation etc.

Skopos rule, coherence rule, fidelity rule and loyalty rule are defined as the four rules of Skopos theory. Among these four rules, Skopos rule is the core one, which means that translation means to produce a TT in target settings or circumstances as expected by target addressees. Fidelity rule requires TT's fidelity to ST and inter-textual coherence. Coherence rule requires that TT should be of certain readability and acceptability to be accepted and even recognized by addressees. The above three rules were put forward by German linguists Hans Vermeer, the person who established Skopos theory, while loyalty rule was later put forward by Christiane Nord, one of the representative scholars of functional translation theory scholars in Germany. Loyalty rule focuses on the relationship among translator, author and client, the relationship between target addressees and translation participants. These four rules serve as the basic rules of Skopos theory, among which Skopos rule is the overarching one and other three must be subjected to it.

\subsection{Skopos Theory's Guidance for Sci-tech Translation}

From the perspective of translator, Skopos theory takes translation as an activity, providing a new angle on translation studies and practices, as well as guidance for sci-tech translation. It requires that translators for science and technology should firstly follow the requirement of clients and clarify the identity of target audiences. Due to the objectivity and preciseness feature of EST, in sci-tech translation, it is also required that TT should be composed in the corresponding style and writing norms as the ST in order to transmit the same information as ST and thus fulfill its communicative functions. This must be considered in the selection of translation strategies and skills. 
At the same time, it is also a brand-new method to apply Skopos theory, a western translation theory, in the study on Europeanization in Chinese, a Chinese translation phenomenon. Europeanization has long been abhorred by many scholars for "distorting Chinese grammar" and "destroying the purity of Chinese". However, these critiques never stop Europeanization from penetrating into Chinese. In current situation, even native Chinese people are so accustomed to Europeanized Chinese that many may not be able to realize it when he or she writes or says Chinese in Europeanized way. New findings may be achieved if the rationality and necessity of Europeanization in Chinese are studied from the perspective of Skopos theory.

\section{Analysis of Europeanization from the Perspective of Skopos Theory}

\subsection{Four Rules of Skopos Theory}

\subsubsection{Skopos Rule}

Skopos rule means that the process of translation is determined by the skopos, or in other words, that the end justifies the means. Skopos of translation, however, is definitely not limited to merely one. We classify skopos into three classifications: a) basic skopos of translators (e.g. making a living); b) communicative skopos of TT (e.g. arousing reader's enlightenment); c) skopos achieved through certain translation techniques (e.g. applying literal translation for the purpose of maintaining and interpreting the original special grammar structure). Normally, skopos refers to communicative skopos of TT, which means the communicative function of TT towards target audience in target settings and context.

The basic task of sci-tech translation is to render the original scientific and technical information by target language, so that readers can conveniently acquire this information through reading TT in their language accurately, without being bothered by source language which they do not understand. So, in order to achieve the goal of promoting communication, language used in sci-tech translation should be standardized. Affixes like "xx 化(-ize)", "xx 性(-ility or -ability)" and “抗 xx(anti-)" are commonly used in the composition of scientific and technical terms, which gives the terms the feature of Europeanization. These words, however, exactly indicate the stability and conciseness of sci-tech texts and clearly render the meanings of original terms, achieving communicative skopos smoothly.

The application of Europeanized express or Europeanization is sometimes mistaken for certain skopos achieved through certain translation technique. More directly speaking, apply literal translation for the purpose of maintaining and interpreting English grammar structure. This, however, does not accord with the communicative function of sci-tech translation. Europeanization is in face applied for communicative function.

\subsubsection{Coherence Rule}

Coherence rule means that intra-textual coherence is a must in TT. TT should be of readability and acceptability to make itself understood by target addressees and make sense in target communicative context. In a nutshell, applying merely word-for-word translation from 
the beginning to the end is not appropriate which will make the TT difficult to read and understand. For sci-tech translation specifically, coherence rule means that translator should take the style and norm of sci-tech texts, as well as the target context, into consideration in the selection of words and expression. In addition, translator should also distinguish the style of sci-tech texts from other styles like that of literature or oral language in order to produce accurate, fluent and appropriate TT.

That the usage of conjunctions in Chinese becomes a must is one of reflections of coherence rule. "The Europeanization of conjunctions is embodied in the shifting from random usage to necessary usage." (Wang Li, 1955) Hypotaxis in English is obvious in the usage of conjunctions. In English, conjunctions are applied as the logic sign consciously. If the same is applied in Chinese, the sentence will be with stronger logic and more accuracy. Such Europeanized expressions are of high eepressive function in sci-tech translation and play a significant role in ensuring the accuracy of TT.

The application of conjunctions like “尽管(Although)”, “而且(and)”、“可是(but)” makes the logical relations among sentences more clearly and thus indicate the preciseness of sci-tech texts. Europeanization of conjunctions accords with the coherence rule and it can also be taken as one kind of translation techniques. Europeanization is not definitely going to destroy the coherence rule while it may sometimes contribute to the coherence and consistency of TT, making it conform to its feature of preciseness, accuracy and objectivity. Whereas if Europeanization is the result of blindly pursuing equivalence in sentence structure and at the expense of fluency, the such Europeanization dose not accord with coherence rule. Under such circumstances, the sentence structure should be changed into Chinese norm.

\subsubsection{Fidelity Rule}

Fidelity rule means that there should be inter-textual coherence between ST and TT. This is similar to the concept of faithfulness to ST which is commonly mentioned by other translation theories, but the degree and form of fidelity to the ST depends on the purpose of the TT and the translator's understanding of the ST. Therefore, the selection of language in TT must adapt to the context and be faithful to ST. The same goes for sci-tech translation. To be specific, the output of sci-tech translation should take ST as the core, reproduce the information in ST with faithfulness, accuracy and objectiveness, and render it with as much original language structure and rhetoric devices as possible. In addition, subjective factors not existing in ST should not be introduced. Europeanized translation is the result of too much faithfulness to the ST.

For example, the structure "as ..." which generally refers to the identity of somebody or the nature of something is often translated into “作为... (work/serve as...)”. In fact, the word “作 为" in ancient Chinese generally refers to the behavior of someone and in modern Chinese it normally means the achievement of someone (like 大有作为, reach great achievements). However, the usage of “作为" as the translation of "as ..." is increasingly influencing the modern Chinese and becoming a new norm. This is the reflection of Europeanization's influence on modern Chinese. We native readers do not find it awkward. On the contrary, we find that the logical relations between sentences are clearer and more distinct. 


\subsubsection{Loyalty Rule}

The skopos theory put forward by Vermeer has two major defects. Firstly, people from different cultural backgrounds have different views on what is good translation due to the differences in cultural patterns. In addition, if the communicative skopos according to skopos rule is contrary to author's intention, then we may get no choice but to observe the skopos rule and violate the fidelity rule. In order to solve these two problems and deal with the relationship between the participants of cultural differences and translation behaviors, Nord therefore put forward loyalty rule. Translator has a moral responsibility to the target addressee to explain to them what he has done and why he has done it, and to be loyal to the original author.

Specifically, in sci-tech translation, translator should respect scientific facts, not ignore any scientific information, not arbitrarily change data, not avoid translation of difficult parts, and not produce TT with the translator's own subjective assume. Difficulty in translating is ultimately difficulty in understanding. If the translator can make contact with the author or client, then he or she can ask the author or client to explain the those difficulty, and ask him or her to clarify the meaning of ST before continuing to translate. If translator cannot make contact with the author or client,he or she needs to make full use of the search engine or go to the library to look up relevant reference, trying best to understand foreign words or sentences and then to interpret them in a way that can make readers fully understand. Even if the Europeanization appears finally, it will still be a good version if it can convey the original meaning to the readers.

\subsection{Summary}

Theoretically speaking, Skopos theory plays an important role in the translation of sci-tech texts. It tells us that the translation of scientific articles should be carried out in the following three steps: 1) clarifying the specific purpose of translation and the type of ST; 2) reading the ST and relevant reference; 3) studying and selecting the corresponding translation methods and strategies (Li Shiyong: 2017). Translation strategies are not necessarily limited to "literal translation" and "liberal translation". Of course, the high accuracy and professionalism of scientific text determine that "literal translation" may be a better one, but it is not absolute.

Even under the function of different translation strategies and translation techniques, TT with Europeanized words or Europeanized sentences can be accepted as long as the skopos of translation is realized, the information is accurately conveyed, the requirements of the client or author is followed, and the translation is readable and well understood. The quality of the TT cannot be denied because of the "impurity" of the translation. As for translators, it is necessary to constantly improve their translation skills in practice, to deepen understandings about translation methods and to accumulate scientific knowledge simultaneously with enhancing English ability, so as to improve quality of TT and promote the development of EST. 


\section{Conclusion}

The translation of sci-tech text requires the precision in terminology, the rigor of logic and the norm of style. It is sometimes difficult to accurately and precisely embody the logic in EST if Chinese parataxis is applied, so it is inevitable to turn to translationese for reconciliation. Skopos theory requires translator to accurately grasp the stylistic features, the situational context and socio-cultural context of the ST and the target readers set by the ST, and then use those as the skopos of translation to produce those kinds of TT accepted by target addressees. If certain Europeanized word or sentence pattern helps achieve such skopos, it can be accepted by translators and readers, stand the test of time, and continue to go forward with the development of modern Chinese language.

Therefore, it is inappropriate for us either to take a completely positive attitude towards Europeanization, or to deny its contribution to enriching Chinese expressions. In the process of scientific and technological translation, the europeanization techniques should be reasonably applied to accurately convey the information of the original text and reflect the logic of the original text. Meanwhile, the inappropriate europeanization of Chinese should be avoided to cause the version to be rigid and obscure, violate the coherence rule of skopos theory and undermine the communicative function of the version. To some extent, Europeanization is conducive to the development of Chinese language. However, according to Mr. Yu Kwang-chung, what we need, or at least what we can tolerate, is only the good kind of Europeanization, and the bad kind of Europeanization can only be kept out of the translation. Perhaps, whether the Europeanization is good or not is equivalent to whether the purpose of translation is achieved or not.

\section{Acknowledgement}

The research is financed by National Training Programs of Innovation and Entrepreneurship for Undergraduates. NO. 82618216.

\section{References}

Li Jinxi. (1924). New Grammar of Modern Chinese. Changsha:Hunan Education Publishing House.

Lü Shuxiang. (1980). Eight Hundred Words of Modern Chinese Language.. Beijing: The Commercial Press..

Sun Ying. (2013). The europeanization of Chinese words. Examination weekly (96), 17-18.

Usami Mayumi. (2002). The development of Discourse Politeness Theory. Gengo Selections (12), 1-12.

Wang Haiyan. (2008). The "europeanization" phenomenon of written Chinese from the perspective of semiotics "intersexuality" theory. (Doctoral dissertation, Ocean university of 
China).

Wang Li. (2014). Chinese modern grammar. Beijing: Commercial Press.

Wang Li. (2014). Modern Chinese grammar. Beijing: Zhonghua Book Company.

Wang Li. (2015). Theory of Chinese syntactics. Beijing: Zhonghua Book Company.

Zhu Dexi. (1984). The Lecture Notes of Grammar. Beijing: The Commercial Press.

\section{Copyright Disclaimer}

Copyright for this article is retained by the author(s), with first publication rights granted to the journal.

This is an open-access article distributed under the terms and conditions of the Creative Commons Attribution license (http://creativecommons.org/licenses/by/3.0/). 